\title{
ESTUDO DE CASO: AS RESPONSABILIDADES AMBIENTAIS DE EMPRESAS DE BENEFICIAMENTO DE ARROZ DA CIDADE DE ITAQUI-RS
}

MARQUES, Gisele Dias ${ }^{1}$

RESUMO: O presente estudo foi desenvolvido para a compreensão das medidas tecnológicas de proteção e manutenção do meio ambiente que o setor empresarial do ramo de beneficiamento de arroz utiliza, enfatizando os novos mercados que uma empresa conquista ao adotar um plano de Gestão Ambiental. O objetivo foi identificar estratégias que possam conduzir a melhorias efetivas do desempenho ambiental, social e econômico de empresas de beneficiamento de arroz da cidade de Itaqui e questionar, descrever e interpretar o contexto no qual vêm se desenvolvendo as atividades de Gestão Ambiental destas empresas. O trabalho baseou-se em aspectos fundamentais para o desenvolvimento sustentável e a implantação de energia limpa.

Palavras chave: Gestão ambiental. Desenvolvimento sustentável. Energia limpa

RESUMEN: Este estudio se llevó a cabo para entender las medidas tecnológicas de protección y conservación del medio ambiente que el sector empresarial de la industria de beneficiamiento de arroz usa, puntuando los nuevos mercados que una empresa logra mediante la adopción de un Plan de Gestión Medioambiental. El objetivo fue identificar las estrategias que pueden conducir a mejoras reales en el desempeño ambiental, desarrollo social y económico de las empresas de beneficiamiento del arroz de la ciudad de Itaqui-RS y cuestionar, describir e interpretar el contexto en que se están desarrollando las actividades de gestión ambiental en estas empresas. El trabajo se basó en los aspectos fundamentales del desarrollo sostenible y la implantación de energías limpias

Palabras clave: Gestión medioambiental. Desarollo sostenible. Energia limpia

\section{INTRODUÇÃO}

A consciência social a respeito dos problemas ambientais cresceu significativamente na última década. Entre esses problemas, questões como desmatamento, manejo sustentável, conservação das florestas e respeito às leis ambientais passaram a ter grande destaque.

A inserção da variável ambiental nos negócios, apesar de recente, sinaliza mudanças no setor empresarial. Por várias décadas, a eficiência de uma empresa teve como maior foco seu campo técnico, isto é, o conjunto de aspectos relativos aos seus insumos, processos e produtos. Hoje, porém, a empresa ecologicamente correta, interage com as diversas demandas das partes interessadas, incluindo a opinião pública e as tendências de mercado.

Entre os vários agentes envolvidos na pressão sob as empresas estão o governo, as organizações não-governamentais - ONGs, as comunidades vizinhas, os trabalhadores, os

\footnotetext{
${ }^{1}$ Bióloga - Secretaria Municipal de Meio Ambiente de Itaqui/RS.
} 
consumidores, os fornecedores, os competidores, os pesquisadores e os investidores. Juntos, formam o campo organizacional do setor. E é este campo que irá perceber e interpretar os impactos resultantes das atividades, estabelecendo os limites aceitáveis para sua realização.

\section{AS EMPRESAS E A GESTÃO AMBIENTAL}

Há basicamente três razões para que as empresas tenham buscado melhorar a sua performance ambiental: primeiro, o regime regulatório internacional que está mudando em direção a exigências crescentes em relação à proteção ambiental; segundo, o mercado está mudando (tanto de fatores quanto de produtos); e terceiro, o conhecimento está mudando, com crescentes descobertas e publicidade sobre as causas e consequiências dos danos ambientais (ROSEN, 2001).

Esta reação ao impacto ambiental do desenvolvimento industrial contaminação do ar, do solo e da água por agentes químicos industriais e agrícolas e destruição do habitat de numerosas espécies pela realização de numerosos projetos de infra-estrutura provoca o surgimento das inúmeras organizações ambientalistas, e assim afirma Canisio (1990), que em um mundo tão concatenado como o de hoje a inclinação das ONGs pela postura ambiental de determinado governo pode significar uma alternativa para se influenciar o processo de negociação bilateral com os países desenvolvidos, em especial as grandes potencias na questão ecológica. A busca dessa simpatia poderia vir a ter repercussões nas políticas internas dos diferentes países, que procurariam dar respostas institucionais às pressões externas em favor da preservação e manejo racional do meio ambiente.

O mundo se move em direção a desregulação, às iniciativas privadas e aos mercados globais. Isto exige que as empresas assumam maior responsabilidade social, econômica e ambiental ao definir seus papéis e ações (STEPHAN, 1992).

Para melhoria efetiva de desempenho ambiental das empresas, é fundamental identificar como os atores sociais influenciam as ações ambientais empresariais e de que maneira e porque as organizações adotam determinadas estratégias em respostas a essas pressões.

Em termos sociais, a empresa deve satisfazer aos requisitos de proporcionar as melhores condições de trabalho aos seus empregados, procurando contemplar a diversidade cultural existente na sociedade em que atua além de propiciar oportunidades aos deficientes de modo geral. Além disso, seus dirigentes devem participar ativamente das atividades socioculturais de expressão da comunidade que vive entorno da unidade produtiva. 
Do ponto de vista ambiental, deve a organização pautar-se pela eco-eficiência de seus processos produtivos, adotar a produção mais limpa, oferecer condições para o desenvolvimento de uma cultura ambiental organizacional, adotar uma postura de responsabilidade ambiental, buscando a não-contaminação de qualquer tipo de ambiente natural, o desenvolvimento sustentável e procurar participar de todas as atividades patrocinada pelas autoridades locais e regionais no que diz respeito ao meio ambiente natural.

\section{DESENVOLVIMENTO SUSTENTÁVEL}

A penetração do conceito de desenvolvimento sustentável no meio empresarial tem se pautado mais como um modo de empresas assumirem formas de gestão mais eficientes, como práticas identificadas com a eco-eficiência e a produção mais limpa.

Embora haja mais um crescimento perceptível da mobilização em torno da sustentabilidade, ela ainda esta mais focada no ambiente interno das organizações voltadas prioritariamente para processos e produtos. É um grande avanço, sem dúvida nenhuma, tornando-se um marco o ano de 1992, mas ainda falta muito para que as empresas se tornem agentes de um desenvolvimento sustentável, socialmente justo, economicamente viável e ambientalmente correto (DIAS, 2006).

Dias (2006), reforça que o mais importante na abordagem das dimensões da sustentabilidade empresarial é o equilíbrio dinâmico necessário e permanente que devem ter, e que devem ser levado em consideração pelas organizações que atuam preferencialmente em cada uma delas: organizações empresariais (econômica), sindicatos (sociais) e entidades ambientalistas (ambiental).

Segundo Sanches (1997), as respostas das empresas às questões ambientais podem variar muito, de acordo com o tipo de negócio envolvido, com os problemas ambientais potenciais decorrentes da atividade, com o tamanho da organização e com a complexidade da estrutura corporativa.

Criticando os modelos vagos e contraditórios de responsabilidade ambiental, Entine (1995) concluiu que as práticas éticas nos negócios são mais bem mensuradas pelo caráter demonstrado por uma empresa e seu compromisso com a transparência, do que por sua visão social ou retórica. $\mathrm{O}$ autor citou o caso de empresas que se dizem socialmente responsáveis, porém atuam de forma superficial, dedicando mais tempo e recursos para anunciar suas práticas ditas "verdes" marketing ambiental do que realmente agindo.

Segundo Entine (1995) e Sanches (1997), uma das funções do marketing ambiental é melhorar a reputação das empresas. Por resultados de pesquisas, o maior nível de marketing 
ambiental representa maior capacidade para projetar uma mensagem consistente acerca de suas preocupações para com a sociedade e o meio ambiente, e seriedade por ir além da conformidade com padrões legalmente impostos, o que melhora a reputação da empresa. Com isso, a empresa ganha visibilidade e vantagem competitiva sobre seus competidores.

Além da reputação, algumas empresas estão usando estratégias ambientais para obterem vantagem competitiva seja pela melhoria de custos através do contínuo melhoramento de processos e redução de resíduos (estratégia baseada em custos), seja por alcançar vários segmentos de mercado que são ambientalmente mais sensíveis (estratégia baseada na diferenciação). Diferenciação de produtos e melhoria na imagem da empresa levam a ganhos de mercado, enquanto que melhoria na eficiência de recursos e redução de risco conduzem a reduções de custo, o que podem ou não levar a ganhos de mercado (MILES; COVIN, 2000).

\section{CERTIFICAÇÃO DE QUALIDADE AMBIENTAL}

Segundo Dias (2002), as certificações ambientais são uma forma de evidenciar a qualidade do produto e a responsabilidade ambiental que a empresa tem, afirma também que clientes dos países desenvolvidos exigem em muitos casos uma certificação reconhecida internacionalmente, como a norma ISSO 14000, para alguns produtos. Para se obter a certificação de um modelo de gestão ambiental, como, por exemplo, a série ISSO 14000, a empresa deve implementar ferramentas para monitorar atividade, produtos ou serviços que podem interagir com o meio ambiente, e desenvolver programas ambientais que promovam redução ou eliminação do impacto eventualmente produzido.

Vários estudos de mercado têm demonstrado que os consumidores estão dispostos a pagar preços mais elevados para produtos que comprovadamente contribuem para a preservação do meio ambiente (DONAIRE, 1999). Em vista disto, em alguns países, os produtos verdes são identificados por um selo ambiental, que acabam ajudando os consumidores a identificar os produtos benéficos ao ambiente.

A adesão aos selos verdes é voluntária, eles estão mais estabelecidos nos países onde os consumidores têm maior consciência ecológica (DIAS, 2006). Um dos primeiros foi o selo alemão Blue Angel, que foi introduzido em 1977. O selo canadense Ecologic Choise de 1988 é um dos mais rigorosos. O Japão criou um selo em 1989, o Eco-Mark, que é conhecido pela Associação Japonesa de Meio Ambiente. Nos Estados Unidos da América, há os selos ecológicos Green Cross e Green Seal, que são apoiados por ONGs ambientais (DIAS, 2006). 
A implementação de um gerenciamento ambiental efetivo requer uma abordagem adequada para lidar com um mundo globalmente interconectado, exigindo uma mudança de percepção, pensamentos e valores. Quanto mais são estudadas as questões ambientais, mais se percebe que elas não podem ser compreendidas isoladamente, pelo fato de serem sistêmicas, interconectadas e interdependentes (CAPRA, 1996).

\section{PRINCÍPIOS DA GESTÃO AMBIENTAL}

Segundo Donaire (1999), os princípios da Gestão Ambiental, criado pela Câmara de Comércio Internacional (CCI) são:

Prioridade Organizacional - que tem como objetivo reconhecer que a questão ambiental esteja sempre nas principais prioridades da empresa e que ela é uma questão-chave para o Desenvolvimento Sustentado.

Gestão Integrada - onde integra as políticas, programas e práticas ambientais intensamente em todos os negócios como elementos indispensáveis de administração em todas suas funções.

Processo de Melhoria - que ressalta as melhorias políticas corporativas, os programas e a performance ambiental tanto no mercado interno quanto externo, levando em conta o desenvolvimento tecnológico, o conhecimento científico, as necessidades dos consumidores e os anseios da comunidade, tendo como ponto de partida as regulamentações ambientais.

Educação do pessoal - que tem como objetivo, treinar, educar e motivar o pessoal, no sentido de que possam desempenhar suas tarefas de forma responsável em relação ao ambiente.

Prioridade de Enfoque - que traduz as considerações sobre as repercussões ambientais antes de iniciar nova atividade ou projeto e antes de construir novos equipamentos e instalações adicionais ou de abandonar alguma unidade produtiva.

Produtos e Serviços - atividade que vai desenvolver e fabricar produtos e serviços que não sejam agressivos ao ambiente e que sejam seguros em sua utilização e consumo, que sejam eficientes no consumo de energia e de recursos naturais e que possam ser reciclados, reutilizados ou armazenados de forma segura.

Orientação ao Consumidor - que se resume na prática de orientar e educar consumidores, distribuidores e o público em geral sobre o correto uso, transporte, armazenagem e descarte dos produtos produzidos.

Equipamentos e Operacionalização - que envolve desenvolver, desenhar e operar máquinas e equipamentos levando em conta o eficiente uso de água, energia e matérias - 
primas, o uso sustentável dos recursos renováveis, a minimização dos impactos negativos ao ambiente e a geração de poluição e o uso responsável e seguro dos resíduos existentes.

Pesquisa - que conduza ou apóie projetos de pesquisas que estudem os impactos ambientais das matérias-primas, produtos, processos, emissões e resíduos associados ao processo produtivo da empresa, visando à minimização de seus efeitos.

Enfoque Preventivo - que modifica a manufatura e o uso de produtos ou serviços e mesmo os processos produtivos, de forma consistente com os mais modernos conhecimentos técnicos e científicos, no sentido de prevenir as sérias e irreversíveis degradações do meio ambiente.

Fornecedores e Subcontratados - que tem como objetivo promover a adoção dos princípios ambientais da empresa junto dos subcontratados e fornecedores encorajando e assegurando, sempre que possível, melhoramentos em suas atividades, de modo que elas sejam uma extensão das normas utilizadas pela empresa.

Planos de Emergência - que ressalta o desenvolvimento de planos de emergência idealizados em conjunto entre os setores da empresa envolvidos, os órgãos governamentais e a comunidade local, reconhecendo a repercussão de eventuais acidentes nas áreas de risco potencial.

Transferência de Tecnologia - que contribui na disseminação das tecnologias e métodos de gestão que sejam amigáveis ao meio ambiente junto aos setores privado e público.

Contribuição ao Esforço Comum - que diz respeito a contribuição no desenvolvimento de políticas públicas e privadas, de programas governamentais e iniciativas educacionais que visem à preservação do meio ambiente.

Transparência e Atitude - que propicia diálogo com a comunidade interna e externa, antecipando e respondendo a suas preocupações em relação aos riscos potenciais e impacto das operações, produtos e resíduos.

Atendimento e Divulgação - que mede a performance ambiental. Conduz a auditorias ambientais regulares e averigua se os padrões da empresa cumprem os valores estabelecidos na legislação. Promover periodicamente informações apropriadas para a Alta Administração, acionistas, empregados, autoridades e o público em geral.

\section{VANTAGENS DE OBTER UM PLANO DE GESTÃO AMBIENTAL}

Ocorre que nos últimos anos a gestão ambiental tem adquirido cada vez mais uma posição destacada, em termos de competitividade, devido aos benefícios que traz ao processo 
produtivo como um todo e a alguns fatores em particular que são potencializados.

Entre as vantagens competitivas da gestão ambiental, Dias (2006) identifica alguns benefícios para que este instrumento seja implantado.

Com o cumprimento das exigências normativas, há melhora no desempenho ambiental de uma empresa, abrindo a possibilidade de maior inserção num mercado cada vez mais exigente em termos ecológicos, com a melhoria da imagem junto aos clientes e comunidade. Adotando um design do produto de acordo com as exigências ambientais, é possível torná-lo mais flexível do ponto de vista de instalação e operação, com um custo menor e uma vida útil maior. Com a redução do consumo de recursos energéticos, ocorre a melhoria na gestão ambiental, com a consequiente redução nos custos de produção, ao se reduzir ao mínimo a quantidade de material utilizado por produto, há redução no custo de matéria prima e do consumo de recursos. Quando se utilizam materiais renováveis, empregando-se menor energia pela facilidade de reciclagem, melhora-se a imagem da organização. Com a otimização das técnicas de produção, pode ocorrer melhoria na capacidade de inovação da empresa, redução das etapas de processo produtivo, acelerando o tempo de entrega do produto e minimizando o impacto ambiental do processo, o melhor uso do espaço nos meios de transporte, há redução nesse tipo de gasto com a conseqüente diminuição do consumo de gasolina, o que diminui a quantidade de gases no meio ambiente. $\mathrm{O}$ grau de envolvimento da empresa com a questão ambiental variará em função da importância que a organização da para a variável ecológica.

Toda a empresa que atualmente deseja reconhecimento e ganho de mercado deverá repensar a forma como utiliza os recursos naturais, obtendo tecnologias que sejam benéficas ao meio ambiente e a comunidade, fazendo com isto o reconhecimento do mercado, aumentando lucros e não adquirindo dívidas com o meio ambiente.

\section{METODOLOGIA}

As informações para a avaliação do desempenho das empresas para com as responsabilidades ambientais e o interesse de possuir um plano de Gestão Ambiental foram obtidas através de pesquisa. $\mathrm{O}$ objetivo foi verificar o que a empresa vem desenvolvendo em termos de Gestão Ambiental e competição no mercado.

\section{DESCRIÇÃO E ANÁLISE DOS DADOS}

\section{Características das Corporações}

As empresas visitadas estão estabelecidas na cidade de Itaqui, que se localiza no Rio Grande do Sul, Brasil. A cidade possui como maior fonte econômica a produção de Oryza sativa (arroz), gerando uma concentração de corporações que atuam na área de beneficiamento deste grão.

As empresas visitadas são conhecidas nacional e internacionalmente. Possuem uma extensa área construída e outras unidades fora da cidade. Na visita a campo, se pode observar 
o ambiente proporcionado aos funcionários e a visão que cada um tem da corporação, desta forma foi possível realizar algumas comprovações. As observações são relacionadas a seguir:

- os funcionários zelam a empresa;

- todos os funcionários inclusive os da alta escala estão preocupados com a questão ambiental;

- apesar da preocupação com o meio ambiente, não há uma área específica das corporações que trate deste assunto;

- há equipamentos que diminuem e tratam os resíduos formados pelo processo industrial, mas não são totalmente eficientes;

- no uniforme existem estampado lembretes sobre segurança pessoal;

- toda a água utilizada em processos industriais é tratada;

- há tratamento de efluentes;

- alguns subprodutos são destinados a novo reprocessamento;

- há produção de energia através da queima da casca de arroz.

Analisando os dados observa-se que as empresas mesmo não possuindo uma assessoria específica para tratar do meio ambiente, preocupam-se e realizam atividades que minimizam agressões ao meio que as cerca.

\section{Descrição e Análise dos Dados Coletados}

A coleta de dados foi através de enquete aplicada diretamente com os responsáveis técnicos da área industrial, e a gerentes que possuem uma relação mais efetiva com a questão ambiental, sendo possível levantar dados sobre como é tratada a Gestão Ambiental nas corporações analisadas.

O gráfico que segue, traz todas as informações obtidas no levantamento de dados. Para formular a análise das empresas leva-se em conta a observação feita na visita a corporação e conforme as perguntas do questionário. 


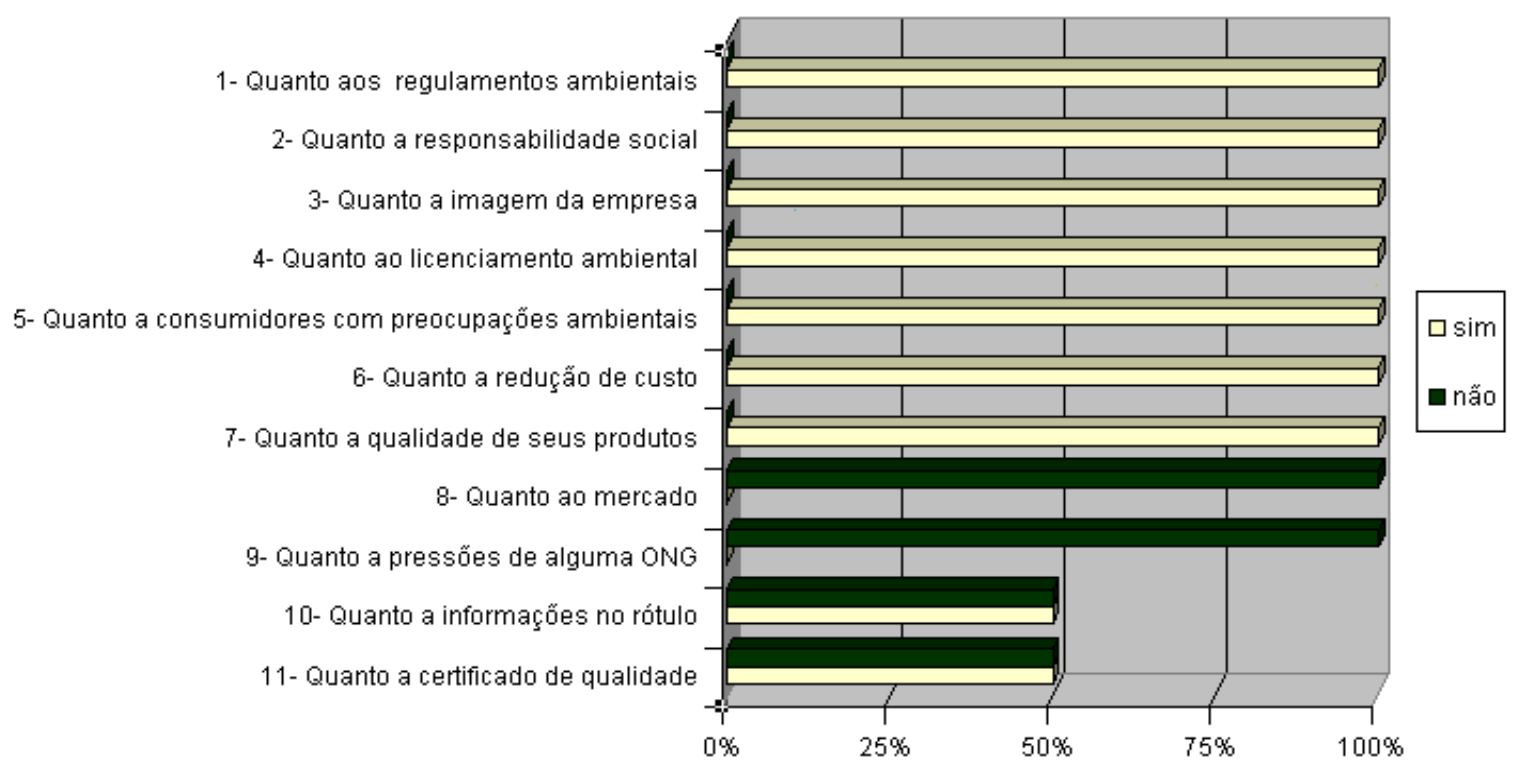

Gráfico 1: Questionário sobre a responsabilidade ambiental das empresas de beneficiamento de arroz da cidade de Itaqui-RS.

Questionando sobre o cumprimento dos regulamentos ambientais (item 1 do gráfico 1) e as práticas do licenciamento ambiental (item 4 do gráfico 1), observa-se que todas as empresas foram positivas ao afirmarem que são comprometidas em atender todos os regulamentos impostos por legislações federais, estaduais, municipais ou até de âmbito internacional e conclui-se que as empresas estão voltadas a uma gestão ambiental efetiva e consciente.

Quanto a responsabilidade social (item 2 do gráfico 1), as empresas demonstraram empenho e responsabilidade com seus funcionários e sociedade em geral, dando assim uma visão positiva de seu trabalho, deixando em alta sua reputação perante a sociedade e mercado.

Assumindo uma postura ambientalmente correta as empresas demonstraram que estão preocupadas com a imagem (item 3 do gráfico 1) que vão passar a seus consumidores e investidores.

Ao responderem que a empresa é preocupada com consumidores que desejam a preservação ambiental (item 5 do gráfico 1), as empresas não só destacam-se pela preocupação com o mercado, mas também reflete uma consciência eficaz ao resolver a problemática da emissão de resíduos, poluição de águas, poluição sonora, entre outros fatores.

Quando respondem que há um programa de redução de custo (item 6 do gráfico 1), as empresas estão contribuindo para o uso sustentável do ambiente, também fazendo-se atuante na área de uso de produtos recicláveis e o uso de energia limpa.

Analisando o ( item 7 do gráfico 1 ), observa-se que um dos princípios de Gestão Ambiental esta sendo posto em atividade, pois os produtos elaborados através de tecnologias 
limpas, que ressaltam o cuidado com o meio ambiente são utilizados para qualificar seus produtos.

Ao buscarem estabelecer um plano de Gestão Ambiental (item 8 do gráfico 1), as empresas não só estão visando o mercado do comércio nacional, mas o internacional, que acarreta mais rentabilidade e credibilidade à empresa.

Quando respondem que as regulamentações impostas para tornarem-se uma empresa "Ecologicamente Correta" (item 9 do gráfico 1), não foi imposta por nenhuma ONG, ressalta a importância que a corporação esta dando a legislação atuante e a preocupação que a empresa tem com o meio ambiente e a sociedade.

Ao responderem, sobre alguma informação no rótulo de seus produtos sobre cuidados ao meio ambiente (item 10 do gráfico 1), observa-se que apenas a metade das empresas possuem este tipo de informação, deixando o consumidor mais informado e a concorrência com desvantagens no mercado. Não é só a pressão dos clientes que torna uma empresa ambientalmente responsável, mas assume forte apelo o entendimento de que o meio ambiente pode se tornar importante ferramenta competitiva e de formação de imagem (DIAS, 2006).

Ao responderem a pergunta que diz respeito a possuir algum certificado que qualifique o produto da empresa como "Produto Ecologicamente Correto" ou "Produto Verde" (item 11 do gráfico 1), 50\% das empresas novamente tornam-se vantajosas em relação a mercado e consumidores, pois este tipo de certificação tem se tornado um estímulo externo de peso para as empresas.

Com estas informações confirma-se que o mercado empresarial que está disposto a crescer e ganhar espaço em âmbito nacional e internacional deve ter um plano de gestão ambiental, um desenvolvimento sustentado e uma prática comercial responsável com seus consumidores, investidores e sociedade em geral.

Conclui-se que as empresas de grande porte de beneficiamento de arroz da cidade de Itaqui-RS estão, caminhando para o rumo certo, respeitando normas, o consumidor e usando o desenvolvimento sustentável como um ponto de referencial muito importante para o crescimento e desenvolvimento destas empresas.

\section{CONSIDERAÇÕES FINAIS}

Após ter realizado este trabalho, ter acompanhado o pensamento sobre a questão ambiental nas empresas de grande porte de beneficiamento de arroz da cidade de Itaqui, conclui-se que alguns princípios de Gestão Ambiental estão sendo aplicado, mas se observa o 
que as leis ambientais propõem, pois uma prática de Gestão Ambiental bem sucedida ainda acarreta uma grande mudança social em termos de desenvolvimento psico-social e cultural.

As empresas podem estar fazendo sua parte, minimizando emissões de partículas, tratando efluentes, usando de técnicas novas para reaproveitarem seus resíduos, mas o mais importante, a matéria prima utilizada nestas empresas, o arroz, ainda é um agente muito degradante do meio ambiente em seu cultivo, pois ainda utilizam-se herbicidas, pesticidas, entre outros produtos que são tóxicos, além do uso do solo sem manejo de culturas.

Para Barkin (1998) e Layrargues (1998), a inserção do setor empresarial no ambientalismo não é resultado de sua conscientização ambiental, mas sim de uma motivação econômica. O ambientalismo empresarial corresponderia a um mero mecanismo de autoregulação, a fim de evitar a crise ecológica. Ao abraçar causas em prol do meio ambiente, as empresas estariam, na verdade, fazendo uma apropriação ideológica dos valores ambientais das ONGs e de outros segmentos da sociedade, para fins de legitimação.

\section{REFERÊNCIAS}

BARKIN, D. Sustainability: the political economy of autonomous development.

Organization \& Environment, v.11, n.1, p.5-32, 1998.

CAPRA, F. The web of life. New York: Anchor, 1996. 347 p.

CNI/BNDES/SEBRAE. Confederação Nacional da Indústria/Banco Nacional de Desenvolvimento Econômico e Social/Serviço Nacional de Apoio às Micro e Pequena Empresas. Pesquisa gestão ambiental na indústria brasileira. Rio de Janeiro - BNDES, Brasília, CNI/BNDES, 1998.

DIAS, R. Gestão ambiental: responsabilidade social e sustentabilidade. São Paulo: Atlas, 2006.

DONAIRE, D. Gestão ambiental na empresa. São Paulo: Atlas, 1999.

ENTINE, J. The messy reality of socially responsible business. At Work, v. 4, n. 3, p. 1-11, 1995.

LAYRARGUES, P. P. A Cortina de fumaça: o discurso empresarial verde e a ideologia da racionalidade econômica. São Paulo: Annablume, 1998. 234 p.

MILES, M. P. COVIN, J. G. Environmental marketing: a source of reputational, competitive and financial advantage. Journal of Business Ethics. Dourdrecht, v..23, pp.299-311, Feb. 2000 . 
ROSEN, C. M. Environmental strategy and competitive advantage: introduction.

California Management Review. Berkeley, Haas Scool of Business. v.43, spr. 2001.

SANCHES, C. S. Evolução das práticas ambientais em empresas industriais: um modelo genérico. In: ENCONTRO NACIONAL SOBRE GESTÃO EMPRESARIAL E MEIO AMBIENTE, 5, 1997, São Paulo. Anais... São Paulo: Fundação Instituto de Administração da Universidade de São Paulo/ Fundação Getúlio Vargas, 1997. p .43-62.

SENGE, P. M. A Quinta disciplina. 12.ed. São Paulo: Best Seller, 1990. 351 p.

VERDUM, R; MEDEIROS, M. V. Rima, relatório de impacto ambiental: legislação, elaboração e resultados. Porto Alegre: ed. Universidade/ UFRGS, 2002. 4. ed. 